\title{
Guidelines for Using Pilot Projects in the Fourth Industrial Revolution
}

João Barata

CISUC, Department of Informatics Engineering; ESTGOH

University of Coimbra

Pólo II, Pinhal de Marrocos, 3030-290 Coimbra, Portugal

Email: barata@dei.uc.pt

\section{Paulo Rupino da Cunha}

CISUC, Department of Informatics Engineering

University of Coimbra

Pólo II, Pinhal de Marrocos, 3030-290 Coimbra, Portugal

Email: rupino@dei.uc.pt

\section{Sharon Coyle}

Business Information Systems

University of Sydney Business School

Australia, NSW 2006

Email: sharon.coyle@sydney.edu.au

\begin{abstract}
Pilot projects are popular in companies for experimenting with industry 4.0 concepts. However, few studies have addressed the specificities of piloting transformation, whose requirements are quite different than those for implementing a project with clear goals. Pilot projects can be used for the purpose of exploring, demonstrating, optimizing and disseminating solutions. In this paper we identify the role of pilot projects in digital transformation and define a successful pilot project so that it transcends to a full project. We provide accessible guidelines for the deployment of pilot projects in industry 4.0, drawing from a structured literature review and from lessons learned in an action research project implementing mixed reality in household ceramics production. A sound approach to pilot projects is important to reduce unknowns and risks in ensuing full projects and to contributing to organizational knowledge, offering an opportunity to rethink business strategies and train employees in digital transformation.
\end{abstract}

Keywords fourth industrial revolution, industry 4.0, digital transformation, pilot projects, mixed reality. 


\section{Introduction}

The ongoing fourth industrial revolution (referred to as industry 4.0 or i4.0) promises radical transformations in industry worldwide. It can be defined as the phenomena of digital transformation in industry supply chains, focusing on the individualization and decentralization of production systems, the integration of intra/inter organizational business processes and the adoption of new emerging technologies, such as autonomous robots, mobile systems, big data, Internet of Things, cloud computing, or mixed reality (Moeuf et al. 2018). The adoption of industry 4.0 is priority for industry managers, who are pressured to implement pilot projects in their organizations in order to test and steer digital transformation efforts (Bauer et al. 2016; PwC 2016).

Pilot projects can be defined as "mini", small scale projects with the aim of evaluating feasibility and steering for full project developments (Lancaster 2015; Zbrodoff 2012). The importance of pilots for large project deployment is well documented. For example, to explore opportunities for future developments, minimize the risk of unexpected events, identify the benefits/difficulties of a project, and to assess the impact of interventions (Dremel et al. 2017; Fosso Wamba and Takeoka Chatfield 2011). Nevertheless, industry transformations involve "high-tech" investments and supply chain integration, creating difficulties for the adoption of traditional project management practices that put excessive emphasis on planning and control (Pajares et al. 2017). Technological advances and the uncertainty of their utility in practice increases the emphasis of 'emergent' projects (rather than 'predictive') whereby the need to understand risks increases (Williams 2017). This reality has blurred the vision of traditional pilot projects as mere "antecedents" of full projects. In fact, the literature reveals that the ongoing fourth industrial revolution is being implemented in practice as a sequence of multiple projects due to a lack of a universal approach to deal with the phenomena (Ganzarain and Errasti 2016).

To overcome the limitations of traditional project management, agile approaches have been proposed in different areas, most notably of which is software development (Dybå et al. 2014). These approaches suggest collaborative, iterative, and incremental advances. However, there are risks associated with evolving iteratively through large-scale, eventually expensive, and sometimes unrelated projects with uncertain results. The plethora of technologies involved in Industry 4.0 (e.g. big data, $3 \mathrm{D}$ printing, mixed reality) and its novelty in some sectors requires testing potential impact and evaluating organizational impact (Lasi et al. 2014). This leads to an expanding number of pilot projects and a necessity to integrate their use in digital transformation efforts. Contrasting with the third industrial revolution that focuses on introducing computers and automating processes, i4.o involves a deeper integration between physical and digital worlds. The increasing complexity of cyber-physical transformations and the social impacts in industry requires (1) feasibility studies in different sectors of the economy, (2) guidelines to assist full project deployments, and (3) a deeper cooperation between industry departments and external stakeholders.

The above mentioned challenges and the conviction that "digital transformation cannot be mastered in waterfall mode nor in blind flight" (Gimpel et al. 2017) have inspired our research questions:

- RQ 1. How can we classify pilot projects for digital transformation in industry 4.0?

- RQ 2. What defines a successful i4.o pilot project so that it transcends to a full project?

The next section introduces our research approach. In section 3 we include a review of related literature in pilot projects and their adoption in digital transformation settings. Subsequently, we present a pilot project with the aim to adopt mixed reality in the traditional sector of household ceramic production. Section 5 discusses the results and proposes guidelines to deploy pilot projects in industry 4.0 transformation. We close with study limitations and opportunities for future research.

\section{Method}

We selected action research as our research approach to study pilot projects in industry transformation initiatives. Action research is suitable for multifaceted organizational problems, considering their social and technical nature (Baskerville and Wood-Harper 1996). We have followed its canonical format (CAR), characterized by the five phases of Diagnosing, Action planning, Action taking, Evaluating, and Specifying learning (Susman and Evered 1978). Action research is “(...) one of the few valid research approaches that researchers can legitimately employ to study the effects of specific alterations in systems development methodologies. It is both rigorous and relevant" 
(Baskerville and Wood-Harper 1996). To ensure rigor and validity, we have relied on the principles proposed by Davison et al. (2004). One of these principles is the definition of a frame of reference before initiation, which we have established using a review of important literature about pilot projects. This is presented in the next section and supports the discussion of our first research question (RQ 1): "how can we classify pilot projects for digital transformation in industry 4.o?" and provides the foundations for action planning in section 4.

\section{Literature Review}

We performed a structured literature review in Web of Science, Scopus and Google Scholar. The combination of keywords included "pilot project", "industry 4.0" but also related terms such as "digital transformation" and "pilot study" (for example, "pilot project" AND "digital transformation" in Web of Science returned 24 results using topic search on July $9^{\text {th, }}$ 2018). We have included papers written in English and excluded non-peer-reviewed articles. Our purpose was to identify pilot projects explicitly developed for industry 4.0 and gather inspiration to propose guidelines for their implementation. Subsequent sections identify key characteristics of pilot projects. Next, we discuss how this particular classification of projects has been used for digital transformation.

\subsection{Pilot Projects}

A pilot project aims to evaluate feasibility, assess and assist process design and guide dissemination, by describing the situation in detail (Eldridge et al. 2016; Kistin and Silverstein 2015; Zbrodoff 2012). Therefore, pilot projects must be managed differently when compared to full, mature projects because the goals may be to identify opportunities for the main project or to test particular elements of a larger plan (Zbrodoff 2012). We agree with Bassi (2010) when she states that a "pilot will be a success if executed correctly" and provides "results that are reliable (whether 'positive' or 'negative')". The author highlights that piloting is not a synonym of incremental deployment and that a pilot project is not the first phase of a larger scale project. In fact, pilots have a learning purpose, to be better positioned to adjust and improve a larger project, reduce associated risks and prepare project team members (Bassi 2010).

There are recommendations for the development of pilot projects in Australia's local governments. For example, Moretti and Spoehr (2017) suggests a stage-by-stage proposal: consulting with key stakeholders, designing projects capable of producing evidence, and analysing available options (analysis, forecasting and impact), adopting a collaborative approach, sharing and promoting the findings. Experimental approaches in policy development can serve multiple purposes such as exploring directions, verifying the effect of specific policies, demonstrating/legitimizing, or promoting the results of specific policies (Ko and Shin 2017).

There are two ways to use a pilot study in social research: (1) as a feasibility study, preceding the larger project; and (2) a pre-test of a specific research instrument. Pilots have the advantage of reducing risks, and identifying potential problems and opportunities for the main project (Pajares et al. 2017; Zbrodoff 2012). Nevertheless, there are also potential limitations of pilots, such as the lack of funding and the risk of wrong predictions to guide future interventions. Some reasons to conduct pilot studies include feasibility analysis, guiding the main project design, collecting preliminary data, team training or convincing stakeholders about the project interest (Kaur et al. 2017; Lancaster 2015).

Pilot projects can be proposed at national, sectorial or company levels, as suggested in Feng et al. (2018) for the Chinese industrial revolution process. An example of pilots addressing the textile sector is presented by Kemper et al. (2017). There are also Universities creating pilot factories of the future, for example TU Wien Pilot Factory Industry 4.o (PFI40) that serves as a platform for research (Ansari et al. 2018). The purpose and characteristics of pilot projects vary in each case. At a national level, large-scale scenarios can be used to test interactions between different elements of major supply chains, inter-organizational communications and the development of national policies (Li 2018). An example of a national pilot project in Australia for Industry 4.0 higher apprenticeships is presented by Loveder (2017), which involves industry and academic partners. Sector-specific pilots can also be used to identify the potential of digital transformations and disseminate the results to other companies. In the case reported by TU Wien, the purpose is to create a simulation environment to assist research, providing greater potential for company-level interventions, contributing to new business models and business process redesign.

Pilot studies are extensively used in healthcare. For example, Kistin and Silverstein (2015) discuss the importance and potential misuses of this type of intervention (e.g. testing hypothesis with insufficient sample sizes). According to the authors, the main goal of pilot studies in clinical trials include testing 
logistical aspects of the main project, optimizing its design, identifying barriers and facilitators, as well as exploring opportunities (Kistin and Silverstein 2015). We can also find practical guidelines to deploy ICT with pilot projects in other sectors of the economy such as the education sector (Bassi 2010). However, despite its popularity for industry 4.0, we could not find publications that present guidelines for pilot project design in industry 4.0 transformation processes.

Project management literature extends the concept of "feasibility/decision to proceed" and considers other possible outputs of pilot projects, namely, "a fully useable product, service or process; and/or a template to create or replicate" (Zbrodoff 2012). In both cases - social research and traditional project management - it is possible to identify the perspective of "decision support" (decision to go further, test feasibility before or during main project execution) and "operational guidance" (templates, product/service output), with a key priority: produce knowledge and contribute to future developments (Zbrodoff 2012). However, this is not always the main priority for industry managers, whose focus is primarily on fast results and concrete improvements of their processes and products.

\subsection{Pilot Projects in Digital Transformation Initiatives}

Major consulting companies recommend pilot projects as an important step for digital transformation initiatives. For example $\mathrm{PwC}$ suggests how pilot projects can "establish proof of concept and demonstrate business value" ( $\mathrm{PwC}$ 2016), while McKinsey highlights their importance for impact estimation (Bauer et al. 2016). One significant reason for using pilot projects is that "a large-scale Industry 4.o rollout requires major investments in the overall technology stack" (Bauer et al. 2016). Nevertheless, the interference of external consultants / ICT companies in pilot projects also presents risks of biasing the results or turning the pilot into a "sales pitch" for new products (Bassi 2010).

An iterative approach for industry 4.0 is presented in Khan and Turowski (2016), starting with the definition of the goals that need to be achieved. A cycle evolves in nine phases that are aligned with the Plan-Do-Check-Act approach and includes proofs of concept and continuous learning (Khan and Turowski 2016). The year-long pilot project presented by Flatscher and Riel (2016) highlights the importance of creating the project team and a shared understanding of the topic. This initial phase (a) can be compared to the goals and strategy definition presented in Khan and Turowski (2016). The case evolves to (b): the design of the "to-be" situation; (c): describing "as-is"; (d): identifying the gaps between both $b$ and c; (e): clustering the deviation causes, and (f): describing each field of action, resources, and specific actions for each field.

Pilot projects can be implemented as controlled environments for i4.o, for example, a pilot city (Li 2018) or a pilot factory (Ansari et al. 2018). Pilots can be implemented for demonstration purposes, describing situations or proofs of concept. Pilot projects can also be implemented as a process to achieve the desired transformation (Dremel et al. 2017). Finally, pilot implementations are important for illustration/dissemination, as it happens in Alexopoulos et al. (2016), to exemplify the proposal of context-aware computing. Although we see the interest and relevance of all these possible applications of pilot projects, there are also potential limitations in their use, for example, to prove the benefits of specific projects in all its extension (Kistin and Silverstein 2015).

There are differences in the various global initiatives aimed at revolutionizing the industry with i4.o. For example, Made in China 2015 has selected the Ningbo as a pilot city "to speed up the construction of its own industrial and manufacturing capability, collaborate with regional innovation systems, personnel training systems, and policy support systems, to create a healthy ecological environment and achieve diversity in development" (Li 2018). In the equivalent European Industry 4.0 initiative we could not find a similar approach. In fact, while the implementation phases of industry 4.0 are not clearly defined, Made in China 2025 has clear goals and indicators (Li 2018).

Pilot projects also play a crucial role at company level, for example, in the digital transformation of Audi AG (Dremel et al. 2017). In their five-year evolution towards big data analytics, the initial two stages (over four years) included proofs of concept. Short term pilots were used (1) to identify the data analytics demands of each business unit (stage 1), (2) as "illustrative pilot cases presented at a steering committee for strategic sales initiatives" (p.85) to demonstrate the potential of big data, (3) to prepare the business cases for digital services (stage 3 - leveraging), and (4) to analyse specific data, create predictive capabilities and leverage car data.

There are four main purposes to adopt pilot projects in i4.o, namely, (1) explore emergent scenarios, (2) demonstrate feasibility, (3) optimize a specific situation proposing design principles (e.g. tune project plans), or (4) disseminate results that are important to a specific target group (e.g. roll-out). The most prevailing perspective points to pilot projects as "contribution for knowledge creation" while full projects provide a "contribution for company strategy". We also found a prevalence of 
technological focus in current industry 4.0 pilot projects (test the adoption of technologies in specific contexts) lacking studies that evaluate the social and organizational implications and the definition of guidelines in conducting pilot projects. The next section presents a recent pilot project developed in our action research project (Susman and Evered 1978).

\section{Piloting Mixed Reality Adoption in Household Ceramics}

This pilot project is part of a larger program aimed at studying and implementing industry 4.0 in traditional sectors of the economy. In this cycle, our research interest was the adoption of three main industry 4.0 technologies in a household ceramic company (HC), namely, mixed reality, cloud and mobile. We knew this company from past projects and their interest in conducting industry 4.0 pilot projects provided an opportunity to contrast our literature findings with a real situation.

\subsection{Research Setting: Digital Transformation in a Traditional Industry}

HC is a small household ceramic company created twenty-eight years ago. Their production was entirely built to client specifications and they have only recently considered strategies in exploring their own design. They employ fifty-four persons and have revenue of 2.5 M USD / year, exporting the majority of their production. The company established partnerships to create innovative products that include a mixture of ceramics and other materials (such as cork). Industry 4.0 is now a priority to HC managers that seek opportunities to differentiate their offerings with new technologies. Examples of HC's portfolio of products are presented in Figure 1.
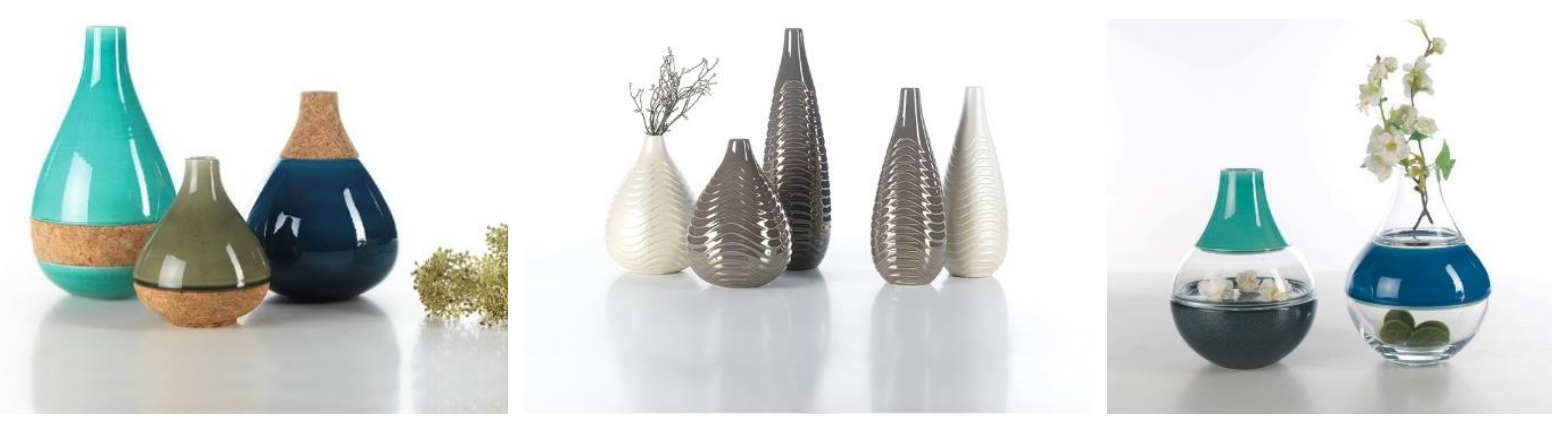

Figure 1: Product portfolio of HC (examples of decorative household ceramics)

Household ceramics are produced with moulds and follow a traditional process of conformation, drying, surface treatment, firing, glazing, finishing and packaging. There are hundreds of different product references and each customer requires specific adaptations. A significant percentage of the company's sales is obtained from contracts closed in international trade fairs. The commercial department is particularly interested in the adoption of new technologies to interact with the customers during requirements analysis (e.g. shapes and sizes, colours, decorations). Providing enduser support is also a possibility (e.g. allowing hotels to test how a specific product looks in their facilities) using mixed reality.

In spite of the vast research in mixed reality technologies we could not find research papers or commercial applications focusing on the use of mixed reality for simulation in traditional household ceramics. Our pilot project also had social goals because company managers needed to sell the idea of industry 4.0 internally (involving commercial department, production, and design), as well as to their customers. It was intended that the pilot project could assist in the (1) internal communication with the team, (2) evaluation of the cost of producing the virtual models (and the potential gains compared to the normal process using physical samples of their products), and (3) dissemination of an image of innovation to their market as leaders in industry 4.0 in ceramics.

\subsection{Action Taking: Mixed Reality in Household Ceramics}

Having defined the main purposes of the pilot project in the previous section, we created a cloud-based mobile app for mixed reality using six different models for testing purposes. 

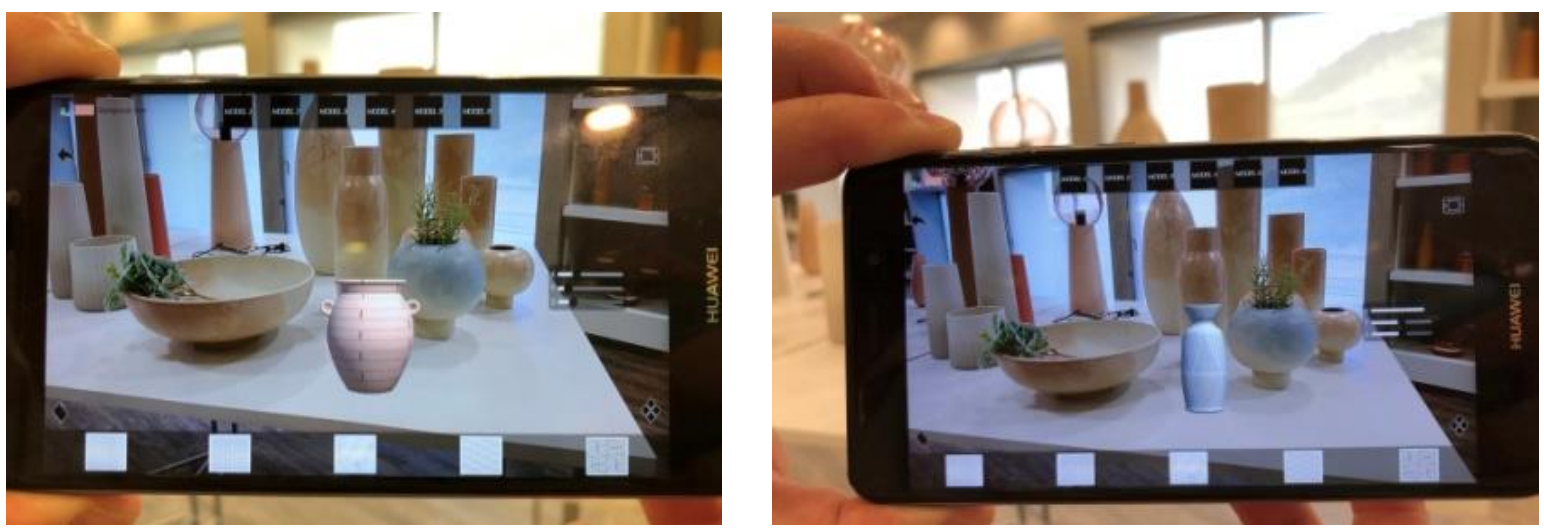

Figure 2: Pilot development of a mixed reality app to simulate ceramic models (simulating two different model shapes in specific product lines)

Figure 2 illustrates the use of mixed reality to simulate different models in a specific environment (e.g. to contrast with other forms of the same product line). A menu on the top of the smartphone display enables selecting a different shape that can be evaluated when placed in real context. HC does not yet have many products with $3 \mathrm{D}$ representations but this is expected to change rapidly since they have recently purchased a $3 \mathrm{D}$ printer which they will use to create samples (for their customers) from digital 3 D files. Besides placing virtual models in real contexts, we also developed additional functionalities for simulation in the app which are represented in Figure 3.
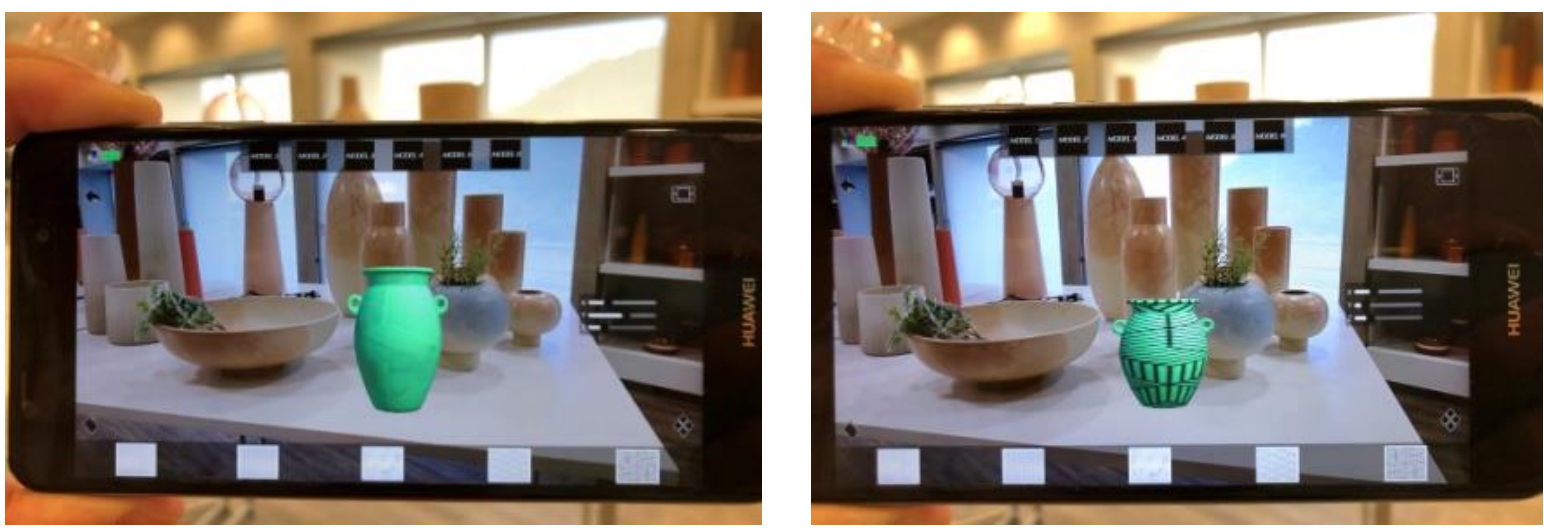

Figure 3: Simulating Dimensions, Colours, and Patterns (green virtual model incorporated in a real showroom; changing dimensions on the leftmost image and simulating patterns on the right)

Figure 3 presents the option to change dimensions, colours or patterns that can be applied to the ceramic product. It is possible to compare the virtual models with existing real models and identify improvements. The interface is simple and accessible to the customers, enabling the creation of screenshots of the desired product to send to the factory. The development of this pilot project had social and technical implications as we describe in the next section.

\subsection{Results and Recommendations}

Having described the client system infrastructure, our action plan to implement a pilot project for mixed reality in ceramics, and conducting action to produce change (Davison et al. 2004; Susman and Evered 1978), it is now important to evaluate the research results and the implications for theory and practice. The results of our pilot project were fourfold, as illustrated in Figure 4, in a proposed matrix that clarifies the four types of outcomes that we have identified earlier in our research, namely, (1) exploration, (2) demonstration, (3) optimization, and (4) dissemination. Although it is not indispensable that all pilot projects include the four outcomes, evidence from these four dimensions can contribute to increase the pilot value and discussion of the results. 


\begin{tabular}{|c|c|}
\hline Exploration & Demonstration (proof / benefits / concerns) \\
\hline $\begin{array}{l}\text { To our knowledge, this is the first adoption of } \\
\text { mixed reality in household ceramic industry } \\
\text { supply chain for simulation that takes } \\
\text { advantage of 3D printing proliferation. We } \\
\text { have explored (1) specific technologies for } \\
\text { cloud/mobile/mixed reality development, (2) } \\
\text { potential ceramic model attributes to } \\
\text { simulate in marketing actions and (3) } \\
\text { customers' expectations. }\end{array}$ & $\begin{array}{l}\text { We have demonstrated the project benefits in the specific } \\
\text { context of these traditional products. On one hand, it is } \\
\text { possible to adopt mixed reality in ceramic production, taking } \\
\text { advantage of the increasing use of } 3 \mathrm{D} \text { printing (and, } \\
\text { consequently, of a growing } 3 \mathrm{D} \text { digital model database), } \\
\text { promoting the collaboration between the design department, } \\
\text { production, and marketing. The technology simplifies } \\
\text { simulation and use of digital portfolios, overcoming the obvious } \\
\text { limitations of transporting multiple real products to limited } \\
\text { space trade fairs. On the other hand, colour simulation is still } \\
\text { artificial when compared to real samples of the materials. } \\
\text { Pattern simulation may exhibit problems depending on the } \\
\text { format of the source 3D model file and UV mapping. }\end{array}$ \\
\hline Dissemination (internal / external) & Optimization (social / technical) \\
\hline $\begin{array}{l}\text { The pilot project was useful to communicate } \\
\text { the company strategy for industry } 4.0 \text { and the } \\
\text { potential of mixed reality technologies. Being } \\
\text { a traditional company, some of the employees } \\
\text { and other stakeholders (e.g. senior } \\
\text { shareholders, some customers and suppliers } \\
\text { of raw materials for ceramic decoration) were } \\
\text { not aware of i4.o potential. }\end{array}$ & $\begin{array}{l}\text { The app was iteratively improved to include a model database } \\
\text { for scalability, ensuring that the solution could be effective with } \\
\text { a larger number of models. Moreover, we have tuned the source } \\
\text { model format to facilitate pattern simulation. The pilot project } \\
\text { was also useful to train specific departments in new tools and to } \\
\text { consider digitalization as a form to improve the company } \\
\text { processes (in particular, in the design and marketing } \\
\text { departments). }\end{array}$ \\
\hline
\end{tabular}

Figure 4: Pilot project matrix: summarizing main outcomes

The results in each cell of the matrix can vary depending on the project characteristics and its maturity. The industry 4.0 strategy was still in the early stages in our case company (pre-full project) justifying a high focus on the topmost cells (exploration and demonstration), however, optimization and dissemination outcomes were also possible to achieve.

The action-taking phase of CAR involved the exploration of mobile and mixed reality technologies using different models that could represent the majority of the product portfolio. Different company experts were involved in the project meetings to prepare the team in industry 4.0, gather improvement feedback and ensure comprehensive evaluation and dissemination of the results.

We concluded that a full project to adopt a mixed reality strategy in ceramic process is viable but it is advisable to take advantage of European funds for research and development due to the potential innovation for SMEs, the possibility to use more advanced virtual reality tools (e.g. smart glasses and smart gloves) and the potential cooperation between academia and industry. A detailed cost-benefit analysis (for example, time consumed for creating 3D models, rework to prepare model files for the app) concluded that leaders in the use of this technology can achieve commercial gains (e.g. in exclusive markets and customers that are using 3D printing as their main prototyping technology), but there are also risks to consider. The recommendations for full project deployment are:

- Process: Integrate the creation of virtual models for 3D printing (during manufacturing) and for interaction with the customer (simulation) in later phases. When creating models for printing, prepare the file format to also be used in the simulations with patterns.

- Social: Train the design department in the manipulation of $3 \mathrm{D}$ models. Disseminate the new app via social networks. Create a video to assist the end users. Create a network of amateur designers - competition with a prize for the best model created with $\mathrm{HC}$ app.

- Technical: Deploy an integrated product database, including functionalities to manage, search, and classify $3 \mathrm{D}$ models. The full project requires dynamic configuration of the product database (we used six models for testing purposes) and a link to a database of models and decorations (patterns). Optimize the simulation including the real dimensions and the equivalent reference for the painting process, according to the selected colour.

- Organizational: Extend the use of mixed reality in different sectors of the factory opportunity for a new pilot project (in parallel with the full project) to assess the potential of the technology for quality control. Since the organizational value of the solution is not yet totally confirmed (impact in sales, customer satisfaction) it is necessary to include other areas of the organization. 
- Communication: Conduct a public presentation of the system in global ceramic trade fairs. There are also opportunities for external communication via social networks and corporate websites. A technical article is another option (e.g. architecture magazines, decoration magazines) to improve the company's brand in the eyes of the end customer. Internally, the pilot project results should be disseminated in workshops involving all the employees.

Our pilot project assessment included a reflection about the company strategy for industry 4.o. We confirmed the potential use of mixed reality, cloud, and mobile technologies for digital transformation of household ceramics. It also contributed to dematerialization of the product design and simulation. The selected technology can be introduced with minor implications for the work process (social, technical and organizational). The company decided to extend a to full project to create the complete system with (1) a $3 \mathrm{D}$ model database, (2) management platform (system to manage the product catalogue, decorations, shapes, files and so on) and (3) smartphone app that allows dynamic product selection.

\section{Discussion}

Learning is a continuous endeavour in action research. This section summarizes key lessons for the development of pilot projects. It is the result of a joint reflection between researchers and partitioners. Pilot projects have the potential to produce value (1) transcending to a full project and (2) contributing to organizational knowledge and strategic reflection. A successful i4.o pilot project depends on its effective contribution for knowledge and practice, preparing and supporting the sequent actions.

\subsection{Focus on the strategic intent}

Strategy blindness was the term used by Arvidsson et al. (2014) to describe a failure to realize a strategic intent of an implemented system capability. The authors point to three factors that can contribute to this effect: "mistranslation of intent, flexibility of the IT artifact and cognitive entrenchment" (Arvidsson et al. 2014). Effective pilot projects must be aligned with company strategy and their contribution (explore, demonstrate, optimize, and disseminate) should be stated. In our CAR, industry 4.0 adoption was the overall strategic intent which allowed us to focus the pilot project on specific technologies and also across organizational changes (such as people training, process redesign). The mere test of mixed reality technologies in a household ceramic context, although potentially interesting for technology providers (e.g. selling $3 \mathrm{D}$ printers or mobile app development) would be a limited perspective for a pilot project. Since "creating knowledge" is one of the main goals of pilot projects, investments must be carefully evaluated and aligned with a strategic intent.

\subsection{Understand the project domain and set up a controlled environment}

It can be stated that "without a thorough and complete understanding of a research domain, a researcher may ask the wrong questions or formulate a meaningless hypothesis" (Nunamaker et al. 1990). Similarly, industry 4.0 pilot projects require a complete description of the industry context. Pilot projects require a controlled environment (preferably, a part of the full project setting). The initial phase of project preparation and design must identify the parameters to be monitored (e.g. product cost, performance, customer satisfaction) and the metrics upon which to assess its achievement during pilot/full project execution. A control group is suggested (e.g. team, process, product) in order to compare the results of pilot implementation. The project team must be trained and a document structure should be implemented (e.g. procedures, project records).

\subsection{Balance full project with the intrinsic value of the pilot project}

"Piloting" does not have to be a mere confirmation that a concept works on a small-scale implementation. Proving that a system can be created (feasibility) also does not mean that it should be done. A pilot project must be of use in guiding a potential full project implementation, preparing the team, the plan, and understanding the potential impact of the system. Therefore, the value of a pilot project transcends the specific purpose of the full project and gains an intrinsic interest when it is incorporated into organizational knowledge. In our case company, the pilot project was designed for a specific technological transformation (mixed reality) but its development produced a rich combination of social and organizational benefits, namely, (1) training, (2) process redesign, (3) marketing strategies and (4) communication of the company's new strategy around digital transformation.

Depending on the lifecycle stage of the full project (pre-during-after), the pilot project requires a distinct approach. Pre-project phase in i4.0 requires quick analysis of the results, comparison of 
technological alternatives, and potential impact in the value chain. The priorities are the project plan and team preparation. During project execution, the priorities must be the results of system implementation and internal dissemination. Multiple pilot projects can provide better evidence of the system impact. Post-project should focus on the overall impact of the system and its integration in the i4.o strategy. Nevertheless, the effect of "knowledge creation" makes pilot projects useful during all the remaining stages of the full project, having benefits in being integrated in a pilot project portfolio. Pilot projects create potential for training the project team in new technologies, preparing the full project execution but also testing technologies and minimizing the risk of errors in future actions.

\subsection{Conduct a multidimensional assessment}

Our pilot project considered three main assessments. First, we conducted a deep assessment of the intervention domain and related literature. Second, we used the pilot project matrix to identify outcomes for (1) exploring, (2) demonstrating, (3) optimizing, and (4) disseminating. Third, we made recommendations for the next phases. A successful i4.o pilot project requires reflection about the process (how), social (e.g. people training), technical (e.g. which technologies), organizational (e.g. business model impact), and communication strategy (in some cases, it is important to conceal strategic information from business competitors). In our case company, the pilot project was useful to train the full project team, redesign the marketing process to include mixed reality technology and identify metrics to monitor full project execution (e.g. time to create a 3D model).

\subsection{Unleash the power of pilot projects for communication and dissemination}

Industry 4.0 is an emergent concept. Therefore, it is still necessary to clarify the importance of digital transformation inside the organization (e.g. to involve different departments in the process) and outside, for example, to specific partners and most importantly, to customers. A controlled environment facilitates the selection of relevant information and the selective dissemination of pilot project results. During our pilot project we have evidenced improvements in industry 4.0 awareness and the need to cooperate between departments (e.g. design, and production). The participative approach to marketing innovation strengthens the perception of the customers' needs inside the factory, and the contribution of industry 4.0 achieves competitive advantages in the market. It was an opportunity to train the team in i4.o technologies and prepare future projects to innovate in traditional products. The context of "knowledge creation" is more favourable for documenting and communicating the results when compared to the complexity of full project implementation with enormous pressure to achieve tangible results for the organization. Consequently, pilot projects can also be useful in later stages of full project deployment (e.g. a small segment of the main project) to disseminate specific results to target stakeholders. We also recommend the creation of a pilot project portfolio for industry 4.0 strategies. The lessons learned in past pilot projects can be valuable later, for example, to assist in the reflection about problems in full projects, opportunities/difficulties in teams' cooperation or as a memorization system (Le Moigne 1975) of the digital transformation process of the organization.

\section{Conclusion}

Our paper has two main contributions to the areas of project management and industry 4.o. First (RQ 1), it selects four key roles of pilot projects in digital transformation for (1) exploring, (2) demonstrating, (3) optimizing, and (4) disseminating. These roles were identified in our literature review and applied in a real situation. Second (RQ 2), we outlined guidelines for successfully transcending to full projects in industry 4.0 scenarios. The findings emerged in a canonical action research (Susman and Evered 1978) project in a traditional ceramics industry with the strategic intent to adopt industry 4.o. Three major assessments are suggested for pilot projects, namely, the complete domain, the pilot project matrix and the recommendations for the full project (if it is decided upon to proceed).

This study has limitations that must be stated. First, there are natural restrictions in the databases and search terms used in our literature review. The research about pilot studies is vast, but the focus in industry 4.0 is scarce. Second, the guidelines for pilot projects are based on a real case but it is a single case, thus other carefully selected cycles can contribute to improve generalization. Third, although we have conducted a joint assessment of the results, the benefits of the pilot project were mainly qualitative and we don't yet have quantitative evidence of cost reduction in the marketing process or specific increases in sales data to report. The company however, considered the results sufficient to decide to proceed to a full project but other evaluations of the pilot project are possible. Industry 4.0 carries additional complexity for project management, especially when involving multiple stakeholders 
(Pajares et al. 2017). This complexity was apparent in our project, which leads to the fourth limitation; we could only involve one customer in this pilot project (albeit an important one).

We identified avenues for future research. First, continue the full project and a parallel pilot project for mixed reality in quality management. The evaluation of customers' receptiveness to new forms of product interaction is another priority. Second, we plan to improve the proposed matrix with additional information to obtain a pilot project canvas. This artefact will aggregate the pilot project information, which is useful for the project team and for communicating with external stakeholders. We hope that the guidelines can assist future pilot projects in digital transformation and we suggest using the pilot project matrix to clarify contributions to the full project and to the intended strategy.

\section{References}

Alexopoulos, K., Makris, S., Xanthakis, V., Sipsas, K., and Chryssolouris, G. 2016. "A Concept for Context-Aware Computing in Manufacturing: The White Goods Case," International Journal of Computer Integrated Manufacturing (29:8), pp. 839-849.

Ansari, F., Erol, S., and Sihn, W. 2018. "Rethinking Human-Machine Learning in Industry 4.o: How Does the Paradigm Shift Treat the Role of Human Learning?," Procedia Manufacturing (23:2017), pp. 117-122.

Arvidsson, V., Holmström, J., and Lyytinen, K. 2014. "Information Systems Use as Strategy Practice: A Multi-Dimensional View of Strategic Information System Implementation and Use," Journal of Strategic Information Systems (23:1), pp. 45-61.

Baskerville, R., and Wood-Harper, A. T. 1996. "A Critical Perspective on Action Research as a Method for Information Systems Research," Journal of Information Technology (11:3), pp. 235-246.

Bassi, R. 2010. "Practical Guide to Pilot Projects and Large Scale Deployment of ICTs in the Education Sector," GESCI: Global e-Schools and Communities Initiative, p. 48.

Bauer, H., Baur, C., Mohr, D., Tschiesner, A., Weskamp, T., and Mathis, R. 2016. "Industry 4.o after the Initial Hype - Where Manufacturers Are Finding Value and How They Can Best Capture It," McKinsey Digital, Whitepaper. (https://www.mckinsey.com/ /media/mckinsey/business functions/mckinsey digital/our insights/getting the most out of industry 4 o/mckinsey_industry_40_2016.ashx).

Davison, R., Martinsons, M. G., and Kock, N. 2004. "Principles of Canonical Action Research," Information Systems Journal (14:1), pp. 65-86.

Dremel, C., Herterich, M. M., Wulf, J., Waizmann, J.-C., and Brenner, W. 2017. "How Audi AG Established Big Data Analytics in Its Digital Transformation,” MIS Quarterly Executive (16:2), pp. 81-100.

Dybå, T., Dingsøyr, T., and Moe, N. B. 2014. "Agile Project Management," in Software Project Management in a Changing World, Springer Berlin Heidelberg, pp. 277-300.

Eldridge, S. M., Lancaster, G. A., Campbell, M. J., Thabane, L., Hopewell, S., Coleman, C. L., and Bond, C. M. 2016. "Defining Feasibility and Pilot Studies in Preparation for Randomised Controlled Trials: Development of a Conceptual Framework," PLoS ONE (11:3), pp. 1-23.

Feng, L., Zhang, X., and Zhou, K. 2018. "Current Problems in China's Manufacturing and Countermeasures for Industry 4.0," EURASIP Journal on Wireless Communications and Networking (2018:1), p. 90.

Flatscher, M., and Riel, A. 2016. "Stakeholder Integration for the Successful Product-process CoDesign for next-Generation Manufacturing Technologies," CIRP Annals - Manufacturing Technology (65:1), pp. 181-184.

Fosso Wamba, S., and Takeoka Chatfield, A. 2011. "The Impact of RFID Technology on Warehouse Process Innovation: A Pilot Project in the TPL Industry," Information Systems Frontiers (13:5), pp. 693-706.

Ganzarain, J., and Errasti, N. 2016. "Three Stage Maturity Model in SME' s towards Industry 4.o," Journal of Industrial Engineering and Management (9:5), pp. 1119-1128.

Gimpel, H., Hosseini, S., Huber, R. X. R., Probst, L., Röglinger, M., and Faisst, U. 2017. "Structuring Digital Transformation - A Framework of Action Fields and Its Application at ZEISS,” Journal 
of Information Technology Theory and Application (4801:1), pp. 31-54.

Kaur, N., Figueiredo, S., Bouchard, V., Moriello, C., and Mayo, N. 2017. "Where Have All the Pilot Studies Gone? A Follow-up on 30 Years of Pilot Studies in Clinical Rehabilitation," Clinical Rehabilitation (31:9), pp. 1238-1248.

Kemper, M., Gloy, Y. S., and Gries, T. 2017. "The Future of Textile Production in High Wage Countries," IOP Conference Series: Materials Science and Engineering (254).

Khan, A., and Turowski, K. 2016. "A Perspective on Industry 4.0: From Challenges to Opportunities in Production Systems," Proceedings of the International Conference on Internet of Things and Big Data (IoTBD), pp. 441-448.

Kistin, C., and Silverstein, M. 2015. "Pilot Studies: A Critical but Potentially Misused Component of Interventional Research," JAMA - Journal of the American Medical Association (314:15), pp. $1561-1562$.

Ko, K., and Shin, K. 2017. "How Asian Countries Understand Policy Experiment as Policy Pilots?, Asian Journal of Political Science (25:3), pp. 253-265.

Lancaster, G. A. 2015. "Pilot and Feasibility Studies Come of Age!," Pilot and Feasibility Studies (1:1), pp. 1-4.

Lasi, H., Fettke, P., Kemper, H. G., Feld, T., and Hoffmann, M. 2014. "Industry 4.0," Business \& Information Systems Engineering (6:4), pp. 239-242.

Li, L. 2018. "China's Manufacturing Locus in 2025: With a Comparison of 'Made-in-China 2025' and 'Industry 4.0,"” Technological Forecasting and Social Change (135:October 2018), pp. 66-74.

Loveder, P. 2017. "Australian Apprenticeship: Trends, Challenges and Future Opportunities for Dealing with Industry 4.o."

Moeuf, A., Pellerin, R., Lamouri, S., Tamayo-Giraldo, S., and Barbaray, R. 2018. "The Industrial Management of SMEs in the Era of Industry 4.0," International Journal of Production Research (56:3), pp. 1118-1136.

Le Moigne, J. L. 1975. "The Four-Flows Model as a Tool for Designing the Information System of an Organization," in Information Systems and Organizational Structure., N. Grochla E., Szyperski (ed.), Walter de Gruyter, Berlin, pp. 324-341.

Moretti, C., and Spoehr, J. 2017. "Valuing Social Outcomes in South Australian Local Government Research Stage Final Report.”

Nunamaker, J. F. J., Chen, M., and Purdin, T. D. M. 1990. "Systems Development in Information Systems Research,” Journal of Management Information Systems (7:3), pp. 89-106.

Pajares, J., Poza, D., Villafañez, F., and López-Paredes, A. 2017. "Project Management Methodologies in the Fourth Technological Revolution," in Advances in Management Engineering, Springer, Cham, pp. 121-144.

PwC. 2016. "Industry 4.0: Building the Digital Enterprise - Engineering and Construction Key Findings." (https://www.pwc.com/gx/en/industries/industries-4.o/landing-page/industry-4.0building-your-digital-enterprise-april-2016.pdf).

Susman, G. I., and Evered, R. D. 1978. "An Assessment of the Scientific Merits of Action Research," Administrative Science Quarterly (23:4), pp. 582-603.

Williams, T. 2017. "The Nature of Risk in Complex Projects," Project Management Journal (48:4), pp. $55-66$.

Zbrodoff, S. 2012. "Pilot Projects-making Innovations and New Concepts Fly," in PMI® Global Congress 2012, Newtown Square, PA: Project Management Institute.

Copyright: (C) 2018 Barata, Cunha, and Coyle. This is an open-access article distributed under the terms of the Creative Commons Attribution-NonCommercial 3.0 Australia License, which permits non-commercial use, distribution, and reproduction in any medium, provided the original author and ACIS are credited. 